Cilt: 5 Sayı: 1 Yıl: 2021

Voume: 5 Issue: 1 Year: 2021

ULUSLARARASI TICARET VE

EKONOMI ARAŞTIRMALARI

Araştırma Makalesi

Research Article

JOURNAL OF DERGISi

INTERNATIONAL TRADE AND ECONOMIC RESEARCHES

\title{
Küresel Isınma, Hidroelektrik ve Rüzgâr Enerji Üretimindeki Artışın \\ Doğal Gaz ithalatına Etkileri: Türkiye Örneği
}

\section{Impacts of Global Warming, Hydroelectric Santrals and Wind Power on Natural Gas Import of Turkey}

Hayriye TaşCl $^{{ }^{* *}}$, Abdulmusa Sönmüş ${ }^{b}$

a Dr., Öğr. Gör., Gaziantep Üniversitesi, SBMYO, Dış Ticaret Bölümü, htasci@gantep.edu.tr, 0000-0002-6402-3151.

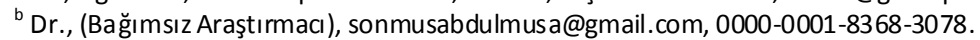

\section{MAKALE BILGISi}

Makale Geçmiși:

Başvuru Tarihi: 10 Kasım 2020

Düzeltme Tarihi: 20 Nisan 2021

Ka bul Ta rihi: 21 Mayıs 2021

\section{Anahtar Kelimeler:}

Doğal Gaz İthalatı, Rüzgâr Enerjisi,

Hidroelektrik Enerjisi,

Nüfus ve Yıllık Ortalama Sıcaklık.

\section{ARTICLE INFO}

\section{Article History:}

Received April, 4, 2020

Received in revised form October, 30, 2020

Acce pted Nove mber, 14, 2020

\section{Keywords:}

Investor Sentiment, Cons umer Confidence Index, Housing Price Index, Behavioral Finance.
ÖZ

Bu çalışmada Türkiye için, doğal gaz ithalat miktarı ile yılın ortalama sıcaklık oranı, rüzgâr ve hidroelektrik enerji kaynaklarına dayalı olaraküretilen elektrik miktarı ve nüfus a rasında ki ilişki 1990-2019 dönemlerini kapsayan yıl lık ve rilerle incelen miş olup Zaman Serileri Anal izi uygul anmıştır. Ya pılan analiz sonucunda yenilenebilir enerji kurulu güç ka pasitele rinin ve özelliklerüzgâr enerjisine ve hidroelektrik enerjiye dayalı elektrik üretimlerinin yakın za ma nlarda artış göstermesine ra ğmen ülked eki enerji talebini ka rşıl a ya ma dığı, özellikle \%90 ora nında dışa bağımlı olduğu doğal gazi thalatınıa zaltmadığı tespit edilmiştir. Küresel ıs ınmanın konutlarda daha az enerji kullanımına yol a zaltacağı beklentisinin halk a rasında enerji kullanımalışkanlıklarında değişikliklerin olmaması ve yoğun teknoloji kullanımı sebebiyle gerçekleşmediği sonucuna varılmaktadır.

JEL Sınıflandırması: Q01, Q40, Q41.

\section{A B S TRACT}

In this research, natural gas import of Turkey between the years 1990 and 2019 is analyzed in facts of alternative energies that are used in Turkey. These alternatives are, hyd roe lectricty a nd wind power which a re producing energy for housholds and indus tries. The impacts of global warming and population on the import of naural gas in Turkey is also a nalyzed as a dditional factors. By using time series analysis, it is found that even though an increase in a lternative energies in Turkey, natural gas import also increases throughout 1990 and 2019. Turkey has not decleared its dependency on natural gas on recent deca de. Na tural gasimport increased around 15 ti mes since 1990 as popula tion growed only \%30 during this time. Turkey still imports $\% 90$ of its need of natural gas today.

JEL Classifications: Q01, Q40, Q41.

\footnotetext{
** Sorumlu yazar/Corresponding author. htasci@gantep.edu.tr
} 


\section{GiRiş}

Doğal gaz rezervleri diğer fosil enerji rezervlerine kıyasla daha bol ve üretiminde bir sınırın olma olasılığı düşük bir enerji kaynağıdır. Fakat bu enerji kaynağı boru hatlarıyla taşınabildiği için ihracatında bazı sınırlılıklar söz konusudur. Yine de küresel doğal gaz ticareti yapmak mümkündür. Bunun için, soğutulmuş süper tankerler ve büyük maliyetlerle inşaa edilmiş yeniden gazlaştırmayı içeren terminaller sayesinde sıvılaştırılmış doğal gaz ihracatı yapılabilmektedir. LNG (Sıvılaştırılmış Doğal Gaz) dünyada doğal gaz ticaretini kolaylaştıran ve daha önce hiç tica ret ya pma mış ülkel eri bile bu konuda birleştiren özel bir öneme sahiptir. Fakat, LNG'nin taşınmasında \%25 lik bir enerji kaybı söz konusudur. Doğal gazı taşıyabilmenin bir başka alternatifi ise onu mentole dönüştürmektedir.

Bu yöntem LNG'den daha ucuz ama enerji kaybı \%40 civarındadır. Kuzey Amerika tek başına Batı ülkeleri içerisinde \%70 oranında doğal gaz tüketen bir ülkedir. Bu sebeple uluslararası doğal gaz ticaretini geliştirmek ve bunun için politik, ticari ve finansal riskleri göze almak önemlidir(Evans, 1978: 177-179). Tablo 1'de dünyadaki doğal gaz üretiminin 1990 yılından 2020 yılına kadar ki dağılımını görmekteyiz. En fazla oranın OECD ülkelerinde olduğu ve bunu başta Amerika olmak üzere Doğu Avrupa ve Avrasya'nın takip ettiğini söyleyebiliriz.

Tablo 1. Doğal Gaz Üretiminin Dünyadaki Dağılımı

\begin{tabular}{|l|c|c|c|}
\hline \multicolumn{1}{|c|}{ Ülkeler } & $\mathbf{1 9 9 0}$ & $\mathbf{2 0 1 4}$ & $\mathbf{2 0 2 0}$ \\
\hline OECD & $\mathbf{8 8 2}$ & $\mathbf{1 . 2 7 0}$ & $\mathbf{1 . 4 0 9}$ \\
\hline Amerika & 643 & 939 & 1.046 \\
\hline Avrupa & 211 & 260 & 220 \\
\hline OECD Dışı Ülkeler & $\mathbf{1 . 1 9 1}$ & $\mathbf{2 . 2 6 7}$ & $\mathbf{2 . 3 9 3}$ \\
\hline Doğu Avrupa -Avras ya & 831 & 858 & 879 \\
\hline Asya & 132 & 460 & 494 \\
\hline Orta Doğu & 95 & 559 & 613 \\
\hline Afrika & 73 & 214 & 230 \\
\hline Dünya Toplamı & $\mathbf{2 . 0 7 3}$ & $\mathbf{3 . 5 3 6}$ & $\mathbf{3 . 8 0 2}$ \\
\hline
\end{tabular}

Kaynak: BP Statistical Review of World Energy June 2002:20.

Hidroelektrik enerji kaynağı dünya çapında çağdaş bir enerji kaynağı olarak bilinmektedir. Az gelişmiş ülkelerin elektrik üretme kabiliyetine olumlu katkıları vardır. Fakat, inşaatının uzun sürmesi ve elektrik enerjisinin taşınmasındaki zorluklar diğer enerji kaynaklarına nazaran rekabetini kısıtlamaktadır. Bu nedenle bu enerji kaynağı daha çok gelişmiş ülkelerde üretilmektedir(Evans, 1978: 182). Büyük potansiyellere sahip olması ve her ülkeye, bölgeye göre değişkenliğinin yüksek olması sebebiyle dünyanın çevresel sorunları üzerinde olumlu etkileri olduğu bilinmektedir(Kalogirou, 2009:35).

Yenilenebilir enerji, güneş, rüzgar, hidroelektrik ve biyokütle dahil olmak üzere birçok enerji biçiminden oluşmaktadır. Bu enerji kaynakları tüketildiğinden daha hızlı üretilebilen enerji kaynaklarıdır(Yao \& Herrerias, 2014: 251).

Tablo 2. Türkiye'nin 2019 Yılı Yenilenebilir Enerji Kaynaklarının Potansiyelleri ve Kapasite

\begin{tabular}{|c|c|c|c|c|c|}
\hline $\begin{array}{c}\text { Yenilenebilir } \\
\text { Kaynaklarımız }\end{array}$ & $\begin{array}{c}\text { Toplam } \\
\text { Kurulu } \\
\text { Güç } \\
\text { Potansiyel }\end{array}$ & $\begin{array}{c}\text { Kurulu } \\
\text { Gücümüz }\end{array}$ & $\begin{array}{c}\text { Kapasite } \\
\text { faktörü }\end{array}$ & $\begin{array}{c}\mathbf{2 0 2 3} \\
\text { Hedefi }\end{array}$ & $\begin{array}{c}\text { Ortalama } \\
\text { Üretim } \\
\text { Potansiyeli } \\
\text { (milyon } \\
\text { kWh/yıl) }\end{array}$ \\
\hline Hidroelektrik & 36.000 & 16.934 & $\% 44$ & 36.000 & 144.000 \\
\hline Rüzgâr & 48.000 & 1.587 & $\% 30$ & 20.000 & 60.000 \\
\hline Güneş & 50.000 & - & $\% 20$ & 3.000 & 7.500 \\
\hline Jeotermal & 600 & 94 & $\% 84$ & 600 & 4.400 \\
\hline Biyokütle & 2.000 & 44 & $\% 80$ & 2.000 & 14.000 \\
\hline Toplam & 136.600 & 136.600 & - & 61.600 & 229.900 \\
\hline
\end{tabular}

Kaynak: ETKB, 2019.

Tablo 2'de Türkiye'nin yenilenebilir enerji kaynaklarının kurulu güç kapasiteleri ve üretim potansiyeli yer almaktadır. Teknolojik gelişmeye bağlı olarak hidroelektrik ve rüzgâr enerji kaynaklarının kurulu güç kapasiteleri diğer enerji kaynaklarına göre da ha fazladır. Güneş enerjisi kurulu güç kapasitesi yüksek olmasına rağmen elde edilen el ektrik üretim potansiyelinin düşük olduğu sonucuna varılmaktadır.

Şekil 1. 2001-2019 Türkiye'nin Sektörel Enerji Tüketimi

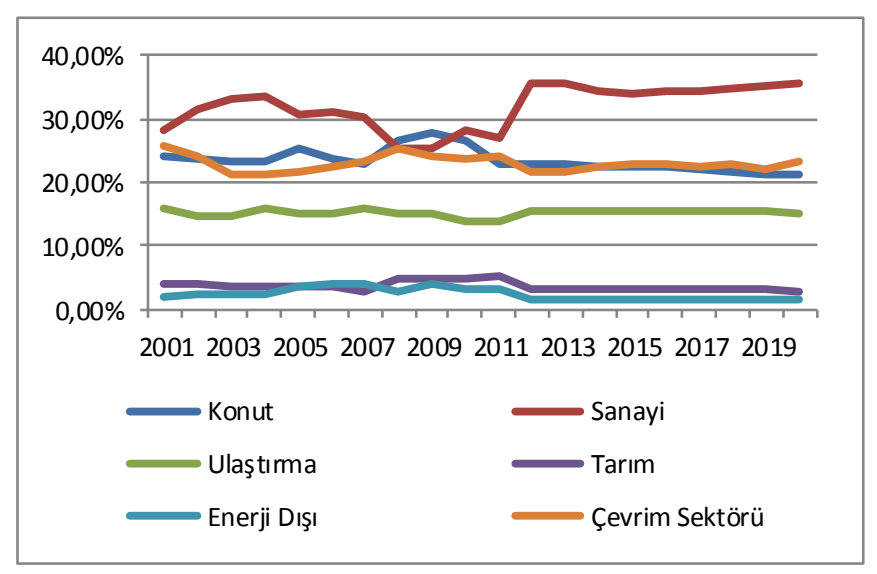

Kaynak: ETKB, 2020.

Şekil 1'de Türkiye'nin sektörel enerji tüketimleri yer almaktadır. Burada en fazla tüketimin sanayi ve konut sektöründe olduğunu ve bunu çevrim sektörünün takip ettiğini söyleyebiliriz.

Küresel ısınma ve buna bağlı olarak ortaya çıkan birtakım güçlükler mevcut enerji sistemlerinin değişmesine neden olmaktadır. Enerji kaynaklarına bağlı olarak meydana gelen bu değişimin başarılı olması siyasi iradenin mevcudiyetine bağlıdır. Sanayi devriminin başlamasıyla birlikte önemi artan petrol ve doğal gazın jeopolitik rekabeti arz güvenliği açısından enerji politikalarının en kritik meselesi olmuştur.

Uluslararası enerji şirketleri ve finansal kurumlar küresel enerji için kilitrol oynamaktadır. Bu nedenle küreselleşen enerji piyasalarının nasıl yapılandırıldığı ve yirmi birinci yüzyılın yeni gerçeklerine uyum sağlamak için 
önümüzdeki yıllarda nasıl değişmeleri gerektiğini anlamak önemlidir (Goldthau \& Witte, 2010: 1-5).

Türkiye'de en hızlı büyüyen enerji kaynağı doğal gazdır. 1987 yılında 0,5 bcm (milyar metreküp) olan tüketim 2007 yılında 35 bcm, 2017 yılında ise 53,9 bcm'e ulaşmaktadır(Erdoğdu, 2010: 211). Dünya'daki tüm ülkeler doğal gaz kullanmaktadır ve bu kaynağa olan talep her geçen gün artmaktadır. Bu sebeple doğal gaz fiyatlarındaki oynaklık beklenmedik bir durum değildir.

Türkiye'de doğal gaz tüketimi petrol ve kömürden sonra 3. sıradadır. İthalatı, nüfus, sanayi ve kentleşme oranı ile doğru orantılıdır. Fakat küresel ısınmaya bağlı olarak tüketimlerinin her geçen gün biraz da olsa azaldığı bilinen bir gerçektir. 2017 yılında Türkiye'deki doğal gaz tüketimi en yüksek seviyesini görmüştür. Bu seviye 2018 yılından sonra gerilemeye başlamıştır. 2018 yılında \%8,6 olan tüketimlerdeki azalış, 2019 yılında \%8 olmuş ve 2020 yılında düşüş eğiliminin devam ettiği izlenmektedir. 2020 yılındaki azalışlarda Covid-19 salgınının etkisi ve beraberinde sanayileşmenin, üretimdeki değişmenin yarattığı etkenler yer alırken çevrim sektörde de tüketimlerin azalması gerilemeyi yaratan ana neden olmuştur(Enerji Görünümü, 2020: 18-19).

Türkiye'de enerji kaynaklarındaki dışa bağımlılığı azaltmanın en pratik yolu yenilenebilir enerji kaynakları üretmek ve petrol, doğal gaz arama ve sondaj çalışmalarını arttırmaktır. Ayrıca, yenilenebilir enerji kaynaklarını olabildiğince etkin kullanmak ve elde etme maliyetlerini düşürmek gerekir.

Türkiye'de doğal gaz üretiminin talebi karşılayamaması arz güvenliğini olumsuz etkileyen bir faktördür. Talebin \%90'ını ithalat yoluyla karşılayan ülkede arz güvenliğini sağlamak amacıyla yer altında depolama faaliyetleri önem kazanmıştır. Ayrıca, kaynak çeşitlendirmesi amacıyla tedarikçi ülke sayısı arttırılmış ve yeni boru hattı projelerine yatırımlar yapılmıştır. Rusya ve Iran'dan sonra en fazla doğal gaz ithalatı TANAP projesi ile Azerbaycan'dan yapılmaktadır.

Yenilenebilir enerji kaynaklarının jeopolitik önemi, kaynaklarını sınırsızlığı, teknoloji, arz güvenliği gibi konular ulusal ve uluslararası enerji politikalarının bir parçasıdır (Mouraviev \& Koulouri, 2019: 14-15).

Tablo 3. Türkiye'nin Doğal Gaz İthalatı (2014-2019)

\begin{tabular}{|c|c|}
\hline Yıllar & (Tj-brüt) \\
\hline 2014 & 1886840,0 \\
\hline 2015 & 1855031,0 \\
\hline 2016 & 1775476,0 \\
\hline 2017 & 2116077,0 \\
\hline 2018 & 1925967,0 \\
\hline 2019 & 1730096,0 \\
\hline
\end{tabular}

Kaynak: www.iea.org/countries/turkey.

Tablo 3'de doğal gaz ithalatının zaman zaman düşüş ve yükseliş̧ler gösterdiğini 2017 yılından sonra ise düşüş eğilimine geçtiğini söyleyebiliriz.
Bu çalışmada cevabı aranan sorular şunlardır:

Küresel ısınma Türkiye'de doğal gaz ithalatını azalttı mı?

Yenilenebilir enerji üretimleri içerisinde rüzgâr enerjisi ve hidroelektrik enerjisinin doğal gaz ithalatına etkileri nelerdir?

Nüfus artışının doğal gaz ithalatıyla ilişkisi var mıdır?

Bu çalışmayı yapmaktaki amacımız; Türkiye'de enerji alanındaki reform sürecini dikkate alarak; nüfus artışıyla birlikte yenilenebilir enerji kaynaklarına yapılan yatırımlar çerçevesinde rüzgâr enerjisi ile hidroelektrik enerji kaynağına bağlı olarak üretilen elektrik enerjilerinin artmasıyla birlikte küresel ısınmaya bağlı olarak doğalgaz tüketimlerinin ve beraberindeki ithalatının nasıl etkilendiğini incelemek ve $\% 90$ oranında doğal gaz bağımlısı olan Türkiye'nin doğal gaz alımlarının azalıp azamadığını hususunda ampirik bir analiz yapmaktır.

\section{LITERATÜR TARAMASI}

Erdoğdu, (2010) çalışmasında Türkiye'nin gelecekteki doğal gaz talebini fiyat ve gelir esnekliğine bağlı olarak ARIMA modeli ile 1987-2007 dönemlerine ait verilerle analiz ederek tahmin etmiştir. ARIMA'nın sonuçlarına göre 2020 yılı için resmi talep tahminleri \%1,3 sapma göstermektedir. Bu kabul edilebilir bir orandır. Başka bir ifadeyle 2007 yılında 100 adet doğal gaz talebi; ARIMA modelleme önerisine bağlı olarak talebin 2020 yılında 190 adet olacağına işaret ederken, resmi tahminler bunun 187.6 birim olacağına işaret etmektedir. Türkiye gibi gelişmekte olan ülkelerin enerji talepleri hakkında daha dikkatli planlamalar yapmaları gerektiği sonucuna varılmıştır.

Arslan \& Solak, (2019) çalışmalarında Türkiye'de yenilenebilir enerji tüketiminin ithalat üzerindeki etkisini 1984-2017 yıllarına ait verilerle Var analizi ile tahmin etmişlerdir. Eşbütünleşme testi sonucuna göre değişkenler arasında uzun dönemli ilişkinin olmadığı, Etki-Tepki fonksiyonuna göre yenilenebilir enerji tüketimindeki artışın ithalatı da arttırdığı sonucuna varılmıştır.

Canbay \& Pirali, (2019) çalışmalarında Türkiye'de savunma harcamaları ve yenilenebilir enerji kullanımının enerji ithalatı üzerindeki etkilerini 1975-2015 dönemlerine ait verilerle ARDL Sınır Testi yaklaşımıyla incelemişlerdir. Savunma harcamalarındaki ve yenilenebilir enerji kullanımındaki artışın enerji ithalatını kısa ve uzun dönemde azalttığı sonucuna varılmıştır.

Doğan \& Tüzer, (2011) çalışmalarında küresel ısınma ve iklim değişikliğinin potansiyel etkilerinin enerji, insan sağlığı, tarım, su kaynakları ve bio çeşitlilikte bir takım değişikliklere yol açabileceği hakkında incelemeler yaparak, bu sorunun çözümü hususunda dünya genelinde bir çevre bilincinin, dayanışmanın ve işbirliğinin geliştirilmesi gerektiği hususunda önerilerde bulunmuşlardır. 
Yılmaz \& Öziç, (2018) çalışmalarında fosil enerji kaynaklarının küresel ısınma ve iklim değişikliğinin en önemli sorunu olduğunu ve ekolojik dengeyi tehdit ettiği gerçeğinden yola çıkarak Türkiye'nin içinde bulunduğu çevre koşulları ve iklim şartları dikkate alınarak yapılan incelemede yenilenebilir enerji potansiyelinin geliştirilmesi gerektiği sonucuna varılmıştır.

\section{EKONOMETRIK YÖNTEM VE ANALIZ}

Türkiye'de yenilenebilir enerji kaynakları içerisinde elektrik üretiminde en fazla potansiyele sahip olan rüzgâr ve hidroel ektrik enerji kaynaklarındaki üretimin, aynı zamanda nüfus artışı ve küresel ısınma şartlarına bağlı olarak doğal gaz ithalatına etkilerini incelemek amacıyla yapılan bu çalışmada 1990-2019 dönemlerine ait yıllık verilerden yararlanılmıştır. Zaman serileri analizinin yapıldığı bu çalışmada elde edilen sonuçlar tablo 3'de sunulmuştur. Türkiye'nin doğal gaz ithalatını azal tacak al ternatif enerji kaynaklarının reel de etki edip etmediğini incelemek amaçlı regresyon analizi yapılmıştır.

Tablo'da, NGi Türkiye'nin doğal gaz ithalat miktarını, W yılın ortalama sıcaklık oranını, WP rüzgâr enerjisi ile üretilen el ektrik miktarını, P Türkiye'nin nüfusunu ve HP ise hidroelektrik ile üretilen elektrik miktarını göstermektedir.

Tablo 3. Zaman Serileri Analizi Test Sonuçları

\begin{tabular}{ccccccc}
\hline Tarih & NGi & LnNGi & W & WP & P & HP \\
\hline 1990 & 124.750 & 5,096041 & 24,10 & - & 53.921 .760 & 1990 \\
\hline 1991 & 154.541 & 5,189044 & 23,00 & - & 54.840 .590 & 1950 \\
\hline 1992 & 169.937 & 5,230288 & 23,20 & - & 55.748 .948 & 2284 \\
\hline 1993 & 189.738 & 5,278154 & 22,90 & - & 56.653 .804 & 2919 \\
\hline 1994 & 203.412 & 5,308377 & 23,30 & - & 57.564 .204 & 2630 \\
\hline 1995 & 263.542 & 5,420850 & 23,10 & - & 58.486 .456 & 3056 \\
\hline 1996 & 318.304 & 5,502842 & 23,90 & - & 59.423 .282 & 3480 \\
\hline 1997 & 380.260 & 5,580081 & 24,20 & - & 60.372 .568 & 3424 \\
\hline 1998 & 393.563 & 5,595014 & 23,50 & 5 & 61.329 .676 & 3631 \\
\hline 1999 & 468.106 & 5,670344 & 23,00 & 21 & 62.287 .397 & 2982 \\
\hline 2000 & 560.616 & 5,748665 & 24,70 & 33 & 63.240 .194 & 2655 \\
\hline 2001 & 614.878 & 5,788789 & 24,90 & 62 & 64.192 .243 & 2064 \\
\hline 2002 & 667.112 & 5,824199 & 24,50 & 48 & 65.145 .367 & 2896 \\
\hline 2003 & 803.993 & 5,905252 & 25,30 & 61 & 66.089 .402 & 3038 \\
\hline 2004 & 843.063 & 5,925860 & 24,90 & 58 & 67.010 .930 & 3963 \\
\hline 2005 & 1.029 .654 & 6,012691 & 23,40 & 59 & 67.903 .469 & 3402 \\
\hline 2006 & 1.171 .307 & 6,068671 & 24,30 & 127 & 68.756 .810 & 3804 \\
\hline 2007 & 1.385 .956 & 6,141749 & 24,90 & 355 & 69.581 .848 & 3083 \\
\hline 2008 & 1.424 .072 & 6,153532 & 26,30 & 847 & 70.418 .604 & 2861 \\
\hline 2009 & 1.373 .446 & 6,137812 & 25,20 & 1.495 & 71.321 .399 & 3092 \\
\hline 2010 & 1.456 .993 & 6,163457 & 25,10 & 2.916 & 72.326 .988 & 4454 \\
\hline 2011 & 1.680 .569 & 6,225456 & 25,90 & 4.723 & 73.443 .250 & 4500 \\
\hline 2012 & 1.759 .024 & 6,245272 & 24,90 & 5.860 & 74.651 .050 & 4975 \\
\hline 2013 & 1.733 .986 & 6,239046 & 26,50 & 7.557 & 75.925 .462 & 5109 \\
\hline 2014 & 1.886 .840 & 6,275735 & 26,30 & 8.520 & 77.229 .256 & 3495 \\
\hline 2015 & 1.855 .031 & 6,268351 & 25,30 & 11.652 & 78.529 .409 & 5774 \\
\hline 2016 & 1.775 .476 & 6,249315 & 25,40 & 15.517 & 79.827 .871 & 5781 \\
\hline 2017 & 2.116 .077 & 6,325531 & 26,20 & 17.904 & 81.116 .450 & 5006 \\
\hline 2018 & 1.925 .967 & 6,284649 & 25,50 & 19.949 & 82.340 .088 & 5154 \\
\hline 2019 & 1.730 .096 & 6,238070 & 26,60 & 21.780 & 83.429 .615 & 7643 \\
\hline & & & & & & \\
\end{tabular}

Kaynak: International Energy Agency, 2021. (www.iea.org/countries/turkey)
Yapılan analizler sonucunda, Türkiye'de yenilenebilir enerji üretimi seçeneklerinin ve bu seçenekler aracılığıyla artan enerji miktarı olmasına rağmen doğal gaz ithalatının da artması dikkat çekmektedir. Tablo 3'de, 1990 yılından günümüze nüfus oranında yaklaşık \%60 oranında bir artış görülmekteyken, doğalgaz ithalatında ise \%1000'lere yakın bir artış görülmektedir. Türkiye'nin son yıllarda yapmış olduğu doğalgaz sondaj faaliyetleri dışında, Türkiye'nin doğalgaz ithalatını azaltacak alternatif enerji seçeneklerin bu analize dayanarak mümkün olmadığı görülmektedir.

Türkiye'de ortalama hava sıcaklığı her yıl artmaktayken doğal gaz ithalatının da artması dikkat çekmektedir. Aynı durum, alternatif enerji kaynakları için de geçerli olmaktadır. Rüzgâr enerji santralleri ve hidroelektrik santralleri her geçen gün artarken, doğal gaz ithalatı artmaya devam etmiştir. Bu artışın sebebi sanayileşme de kullanılan doğal gaz tüketiminin yanı sıra, nüfus artış oranı olarak açıklanabilir. Ancak, regresyon analizi sonucunda, söz konusu alternatif enerji kaynaklarının ve nüfus değişkenlerinin doğal az ithalatına etkisi anlamsız çıkmaktadır. Dolayısıyla, analizlere dayanarak, doğalgaz ithalatını azaltabilecek başlıca bir değişken bulunamamıştır. Nüfus artışı ise doğalgaz ithalatındaki artışı tek başına açıklamada anlamsız kalmıştır.

\section{SONUÇ VE DEĞERLENDIRME}

Birincil enerji ihtiyacının büyük bir kısmını doğal gazdan karşılayan Türkiye'nin nüfus artışına bağlı olarak enerji ihtiyacı her geçen gün artarken, fosil enerji rezervlerinin yetersizliği ile petrol ve doğal gazdaki yüksek maliyetli dışa bağımlılı ekonomik kalkınmayı olumsuz etkilemektedir. Türkiye'nin enerji alanındaki bu bağımlılığının azaltılması için yenilenebilir enerji kaynakları üretiminin arttırılması gerekir. Öncelikle bu alanda yapılan yatırımların arttırılması ve kullanımlarının özendirilmesi önemlidir. Yapılan bu çalışmada yenilenebilir enerji kaynakları içerinde rüzgâr ve hidroelektrik enerji kaynakları üretimlerinin ülkedeki enerji ihtiyacını karşılamada nasıl bir seviyede olduğu ve beraberinde doğal gaz ithalatını azaltıp azaltmadığı incelenmektedir. Inceleme sonucunda Türkiye'de ar-ge çalışmaları neticesinde rüzgâr ve hidroelektrik kurulu güç kapasiteleri yıllar itibariyle artış göstermesine rağmen küresel ısınmaya bağlı olarak doğal gaz tüketimlerinin azalmış olabileceği beklensen de, ülkenin yoğun sanayileşmeye dayalı ekonomik yapısının olması sebebiyle enerji tüketimlerinin azal madığı ve yenilenebilir enerji kaynaklarında artış ol masına rağmen, halkın enerji tüketim alışkanlıklarının değişmemesi ve beraberinde kayıp kaçak oranlarının fazlalığı doğal gaz ithalatını düşürmediği sonucuna varılmıştır. Yani; Türkiye'de rüzgâr enerjisi, hidroelektrik enerji, küresel ısınma ve nüfus artışı ile doğal gaz ithalatı arasında bir bağıntının bulunmadığı sonucuna erişilmiştir. 


\section{KAYNAKÇA}

Arslan, E., \& Solak, A. (2019). Türkiye'de Yenilenebilir Enerji Tüketiminin İthalat Üzerindeki Etkisi. Uluslararası Toplum Araştırmaları Dergisi, 10(17).

https://doi.org/10.26466/opus.521269

BP Statistical Review of World Energy June 2002.

Canbay, Ş., \& Pirali, K. (2019). Türkiye'de Savunma Harcamaları ile Yenilenebilir Enerji Tüketiminin Enerji İthalatı Üzerindeki Etkileri. Akademik Araştırmalar ve Çalışmalar Dergisi, 11(21), 12.

Doğan, S., \& Tüzer, M. (2011). Küresel Iklim Değişikliği ve Potansiyel Etkileri. C.Ü. İktisadi ve Idari Bilimler Dergisi, 12(1).

Enerji Görünümü. (2020).

Erdoğdu, E. (2010). Natural Gas Demand in Turkey. Applied Energy, 87, 211-219.

https://doi.org/10.1016/j.apenergy.2009.07.006

Evans, D. (1978). Western Energy Policy. Palgrave Macmillan UK. https://doi.org/10.1007/978-1-34916016-7

Goldthau, A., \& Witte, J. M. (2010). Global Energy Governance The New Rules of the Game (1. bs). Global Public Policiy Institute, Berlin.

Kalogirou, S. A. (2009). Solar Energy Engineering Processes and systems. Academic Press is an imprint of Elsevier.

Mouraviev, N., \& Koulouri, A. (2019). Energy Security Policy Challenges and Solutions for Resource Effciency. Springer Nature Switzerland AG.

Yao, S., \& Herrerias, M. J. (Ed.). (2014). Energy Security and Sustainable Economic Growth in China. Palgrave Macmillan

UK.

https://doi.org/10.1057/9781137372055

Yılmaz, E. A., \& Öziç, H. C. (2018). Türkiye'nin Yenilenebilir Enerji Potansiyeli ve Gelecek Hedefleri. Ordu Üniversitesi Sosyal Bilimler Araştırmaları Dergisi, 8(3), 10.

www.iea.org/countries/turkey. 